\title{
Degradação ruminal da matéria seca de clones de capim-elefante em função da relação folha/colmo
}

\author{
Alexandre Carneiro Leão de Mello ${ }^{1}$, Mário de Andrade Lira ${ }^{2}$, José Carlos Batista Dubeux \\ Júnior $^{3}$, Mércia Virginia Ferreira dos Santos $^{3}$, Rinaldo Luiz Caraciolo Ferreira ${ }^{3}$, Márcio Vieira \\ da Cunha ${ }^{3}$ \\ 1 Universidade Federal de Alagoas, A.C. Simões BR-101 Norte, km 97, Tabuleiro dos Martins, Maceió - AL, CEP: 57079-970, \\ Tel: : $(0 x \times 82)$ 214-1084. \\ 2 IPA, Av. General San Martin, 1371, Bonji, Recife - PE - CEP: 50761-000, Tel.: (0xx81) 2122-7200. \\ ${ }^{3}$ Departamento de Zootecnia, Universidade Federal Rural de Pernambuco, Av. Dom Manoel de Medeiros, S/N, CEP: 52171-030, \\ Tel.: (0xx81)3302-1554, Dois Irmãos, Recife - PE.
}

RESUMO - Objetivou-se com este trabalho avaliar a influência da relação folha/colmo (F/C) na degradabilidade in situ da MS (DISMS) de clones de capim-elefante. Foram estudados dois grupos de clones de capim-elefante: GRUPO I - Cameroon, Mercker México, Três Rios, Elefante de Pinda e Guaçu/IZ, de alta relação F/C; e GRUPO II - CE 08 A.D., Taiwan A-25, Goiano, CE 03 A.D. e Merc., de baixa relação F/C. Amostras pré-secas e moídas da planta inteira, colhidas aos 60 dias de crescimento no período seco, foram incubadas no rúmen de dois bovinos mestiços nos períodos de 0, 6, 12, 24, 48, 72 e 96 horas, para determinação da DISMS e de suas características. O delineamento experimental utilizado foi em blocos casualizados, em parcelas subdivididas. Não houve diferença significativa entre os grupos de capim-elefante em relação à DISMS. Foram obtidas as seguintes médias para as caratcerísticas de degradação ruminal: 79,$40 ; 69,10 ; 26,90 ; 52,60,20,60 \%$ e $5,50 \% / h$ para degradabilidade potencial, degradabilidade efetiva, fração solúvel, fração potencialmente degradável, fração não degradada e taxa de degradação, respectivamente. A relação folha/colmo não influenciou a DISMS de clones de capim-elefante.

Palavras-chave: degradabilidade in situ, morfologia, período seco

\section{Ruminal dry matter degradation of elephantgrass clones as a function of the leaf/stem ratio}

\begin{abstract}
The objective of this work was to evaluate the influence of leaf/stem ratio (L/S) in the in situ dry matter degradability (ISDMD) of elephantgrass clones. The experiment was carried out at IPA Experimental Station, in Vitória de $\mathrm{St}^{\circ}$. Antão, PE. Two groups of elephantgrass clones were studied: GROUP I (Cameroon, Mercker México, Três Rios, Elefante de Pinda and Guaçu/IZ), characterized by its high L/S ratio, and GROUP II (CE 08 A.D., Taiwan A-25, Goiano, CE 03 A.D and Merc.), with low L/S ratio. Samples of whole plant harvested in the $60^{\text {th }}$ day of growth in the dry period were dried and milled and incubated in the rumen of the two crossbred bovines for 0, 6, 12, 24, 48, 72 e 96 hours to determine the ISDMD and ruminal fermentation parameters. The experimental design was randomized blocks in split-plot arrangement. There wasn't any significant difference between groups of elephantgrass as defined by their ISDMD. The degradation characteristics averaged $79.40,69.10,26.90,52.60,20.60 \%$, and $5.50 \% / \mathrm{h}$ for potential degradability, effective degradability, soluble fraction, potentially degradable fraction, no degraded fraction, and degradation rate, respectively. The leaf/stem ratio did not influence the ISDMD of elephantgrass clones.
\end{abstract}

Key Words: dry period, in situ degradability, morphology

\section{Introdução}

O capim-elefante (Pennisetum purpureum Schum.) tem sido bastante estudado em programas de melhoramento genético em todo Brasil com o intuito de selecionar materiais superiores aos atualmente cultivados, adaptados a cada realidade ambiental do país. As propriedades que se dedicam à pecuária em Pernambuco, em sua maioria, cultivam o capim-elefante (Freitas et al., 2004) e, por isso, melhorias na qualidade da MS dessa gramínea constituem importante objetivo no seu melhoramento genético no estado.

A produção de forragem durante $\mathrm{o}$ ano varia conforme as estações, que, por sua vez, influenciam o crescimento e desenvolvimento da planta. Segundo Lopes et al. (2000), a alta produtividade do capim-elefante na estação chuvosa e 
a redução do crescimento na época seca podem resultar em grandes variações nas características morfológicas.

De acordo com Cherney et al. (1990), a morfologia da planta pode explicar, em parte, as variações na qualidade da forragem. Anatomicamente, as gramíneas são formadas por diferentes tecidos que possuem função específica de transporte de água e nutrientes, sustentação, proteção e outros. Os tecidos, por sua vez, formam os órgãos das plantas, como folhas e colmos, de modo que a composição química de cada órgão influencia a proporção dos diferentes tecidos que o compõem.

As gramíneas possuem variação genética significativa quanto à configuração anatômica e à degradabilidade de seus tecidos (Grabber et al., 2004). De acordo com Queiroz et al. (2000a), a proporção de esclerênquima é a característica anatômica mais correlacionada à degradabilidade da MS. Correlações positivas altamente significativas foram observadas entre a proporção de bainha parenquimática dos feixes vasculares, tecido vascular lignificado e esclerênquima e os teores de FDN, FDA e lignina das gramíneas, enquanto as proporções de mesófilo e epiderme, tecidos em maior proporção nas folhas, se correlacionam negativamente a esses componentes.

Dessa forma, a relação folha/colmo constitui importante característica na avaliação da qualidade de materiais forrageiros (Pereira et al., 2000), uma vez que maior proporção de folhas pode evidenciar material de melhor degradabilidade, em virtude da menor presença de tecidos estruturais indegradáveis ou de difícil degradação, podendo influenciar a dinâmica e a velocidade da degradação da MS pelos microrganismos do rúmem. Assim, é possível que clones de capim-elefante com diferentes proporções de folhas e colmos apresentem diferenças quanto à qualidade da forragem produzida.

Objetivou-se com este trabalho investigar a influência da relação folha/colmo sobre a degradabilidade in situ da MS de clones de capim-elefante no período seco da Zona da Mata de Pernambuco.

\section{Material e Métodos}

Os clones de capim-elefante (Tabela 1) foram implantados na Estação Experimental do Cedro, pertencente à Empresa Pernambucana de Pesquisa Agropecuária (IPA), localizada em Vitória de Santo Antão, Zona da Mata de Pernambuco. A Estação apresenta como coordenadas geográficas $08^{\circ} 08^{\prime} 00^{\prime \prime S}$ de latitude e $35^{\circ} 22^{\prime} 00^{\prime \prime} \mathrm{W}$ Gr. de longitude e encontra-se a $146 \mathrm{~m}$ de altitude. De acordo com observações históricas, apresenta precipitação pluviométrica
Tabela 1- Clones de capim-elefante, Vitória de Santo Antão - PE Table 1 - Elephantgrass clones, Vitória de Sto. Antão - PE

\begin{tabular}{lcc}
\hline $\begin{array}{l}N^{\circ} \text { de ordem } \\
N . \text { of order }\end{array}$ & $\begin{array}{c}\text { Clone } \\
\text { Clone }\end{array}$ & $\begin{array}{c}\text { Procedência } \\
\text { Origin }\end{array}$ \\
\hline 1 & CE 03 A.D & IRI \\
2 & CE 08 A.D & IRI \\
3 & Cameroon & CNPGL \\
4 & $468-76$ ou Mercker México & IPEACS \\
5 & $473-76$ ou Elefante de Pinda & IPEACS \\
6 & Três Rios & CNPGL \\
7 & $454-776$ ou Taiwan A-25 & IPEACS \\
8 & Guaçu/IZ & CNPGL \\
9 & $478-76$ ou Merc & IPEACS \\
10 & Goiano & CNPGL \\
\hline
\end{tabular}

anual de $1.025 \mathrm{~mm}$, com maior concentração entre os meses de março e julho, evapotranspiração de $1.344 \mathrm{~mm}$, evapotranspiração real de $927 \mathrm{~mm}$, umidade relativa do ar média de $67 \%$ e temperaturas máxima absoluta, mínima absoluta e média de 33,$1 ; 18,9$ e $25,4^{\circ} \mathrm{C}$, respectivamente. $\mathrm{O}$ tipo climático foi definido como $\mathrm{C}_{1} \mathrm{~S}_{2} \mathrm{Aa}$ (seco subúmido megatérmico) e o tipo de solo como podzólico vermelho amarelo (PVA) equivalente eutrófico, com topografia predominantemente ondulada (Encarnação, 1980; Anuário Estatístico de Pernambuco, 1991; Thornthwaite \& Matter, 1995).

O solo da área experimental apresenta textura francoarenosa e adequada fertilidade (Tabela 2). Após a análise do solo, a área foi gradeada e adubada com $\mathrm{N}, \mathrm{P}_{2} \mathrm{O}_{5}$ e $\mathrm{K}_{2} \mathrm{O}$ nas proporções de 30, 90 e $60 \mathrm{~kg} / \mathrm{ha}$, respectivamente. Em seguida, foi realizado o plantio dos clones em sulcos de $5 \mathrm{~m}$ de comprimento, espaçados a $1 \mathrm{~m}$, com aproximadamente $20 \mathrm{~cm}$ de profundidade. Cada clone formou parcelas não repetidas de $10 \mathrm{~m}^{2}$. Após a completa implantação, foi realizado corte de uniformização a $30 \mathrm{~cm}$ do solo, ocasião na qual foi aplicada adubação nitrogenada com $100 \mathrm{~kg} / \mathrm{ha} \mathrm{de} \mathrm{N}$.

$\mathrm{Na}$ época seca, de setembro a outubro de 1997, aos 60 dias de crescimento, os clones foram cortados a $30 \mathrm{~cm}$ do solo. Nesse momento, foram tomados, aleatoriamente, cinco perfilhos basais para avaliação da relação folha/colmo, obtida pela separação manual do colmo (colmo+bainha) e da lâmina foliar, cortada à altura da lígula, e pela determinação do peso seco $\left(\mathrm{a} 65^{\circ} \mathrm{C}\right)$ de cada componente, em estufa de circulação forçada.

Foram retiradas amostras da planta inteira em $1 \mathrm{~m}$ linear/ parcela visando caracterizar parte da composição química dos clones por meio das determinações dos teores de FB, FDN e FDA, conforme Silva \& Queiroz (2002). As análises foram realizadas no Laboratório de Nutrição Animal do Departamento de Zootecnia da UFRPE. 
Tabela 2 - Características físicas e químicas de amostras de solo da área experimental, Vitória de Santo Antão - PE

Table 2 - Soil physical and chemical characteristics in the experimental area, Vitória de Santo Antão - PE

$\begin{array}{lr}\text { Característica } & \text { Valor/Interpretação } \\ \text { Characteristic } & \text { Value/Interpretation }\end{array}$

Física

Physical

Densidade aparente $\left(\mathrm{g} / \mathrm{cm}^{3}\right)$ (Bulk density, $\left.\mathrm{g} / \mathrm{cm}^{3}\right)$

1,56

Areia grossa (\%) (Coarse sand, \%)

63,00

Areia fina (\%) (Fine sand, \%)

8,00

Silte (\%) (Silt, \%)

10,00

Argila (\%) (Clay, \%)

19,00

Classe textural do solo (Soil textural class)

Franco-arenoso (Sandy loam)

Ponto de murcha permanente $(\%)$

5,33

Permanent wilting point (\%)

Capacidade de campo (\%) (Field capacity, \%) 11,45

Água disponível (\%) (Available water, \%)

6,12

Química

Chemical

$\mathrm{pH}$

$\mathrm{P}(\mathrm{ppm})$

76,47

2,20

(meq/100g de solo) $\left(\mathrm{Ca}^{++}, \mathrm{meq} / 100 \mathrm{~g}\right.$ of soil)

1,05

$\mathrm{Mg}^{++}$(meq/100g de solo) $\left(\mathrm{Mg}^{++}\right.$, meq/100 $\mathrm{g}$ of soil)

0,00

(meq/100g de solo) $\left(\mathrm{ll}^{+++}, \mathrm{meq} / 100 \mathrm{~g}\right.$ of soil)

0,20

0,07

N (\%)

Materia orgânica (\%) (Organic matter, \%)

1,01

$\mathrm{H}^{+}(\mathrm{meq} / 100 \mathrm{~g}$ de solo $)\left(H^{+}\right.$, meq/100 $\mathrm{g}$ of soil $)$

0,66

0,17

(

1,14

Condutividade elétrica $(\mathrm{dS} / \mathrm{m})$

Electrical conductivity $(d S / m)$ os sacos foram continuamente lavados com água em máquina centrífuga, até que a água se apresentasse limpa. Depois de lavados, foram mantidos em estufa a $105^{\circ} \mathrm{C}$ por 24 horas, sendo novamente pesados.

As características da DISMS foram estudadas por meio do modelo $\mathrm{Dp}=\mathrm{a}+\mathrm{b}\left(1-\mathrm{e}^{-\mathrm{CT}}\right)$ proposto por Orskov \& McDonald (1979), no qual: $\mathrm{Dp}=$ degradabilidade potencial da MS, calculada pela soma de a + b; a = fração solúvel (FS) da MS; $b=$ fração potencialmente degradável da MS (FPD), a determinada taxa; c = taxa de degradação (TD) da FPD; T = tempo de incubação (horas). A fração nãodegradada (FND) da MS foi calculada da seguinte forma: 100 - (FS+FPD).

A degradabilidade efetiva (De) foi estimada com base nas constantes a, b e c por meio da fórmula: $\mathrm{De}=\mathrm{a}+\frac{\mathrm{b} \times \mathrm{c}}{\mathrm{c}+\mathrm{k}}$, em que: $\mathrm{k}$ corresponde à taxa de passagem ruminal do alimento $(\% / \mathrm{h})$, referente a $5 \% / \mathrm{h}$.

Por se tratar de um grupo de clones de capim-elefante com parcelas não repetidas, não foi realizada análise de variância para os caracteres PB, FDN e FDA. Entretanto, foi determinado o intervalo de confiança para a média, com nível de confiança de $95 \%$ de probabilidade, e os coeficientes de variação para essas variáveis.

Para a DISMS, foi realizada análise de variância considerando delineamento experimental em blocos (animais) ao acaso em parcelas subdivididas, na qual os tempos de incubação formaram a parcela e os grupos de clones de capim-elefante representaram as subparcelas. Os grupos foram comparados pelo teste $\mathrm{F}$ a $5 \%$ de probabilidade.

\section{Resultados e Discussão}

O teor de $\mathrm{PB}$ apresentou média de $5,02 \%$, com variação de 3,43 a 6,78\%, para os clones CE 08 A.D. e Três Rios, respectivamente (Tabela 3 ). Em todos os clones, os teores de $\mathrm{PB}$ foram inferiores a 7\%, valor crítico preconizado por Minson \& Wilson (1994) para que não ocorra limitação no consumo voluntário dos ruminantes, promovido por restrições metabólicas no processo energético (Fisher, 2002).

Ressalta-se que os valores de PB neste trabalho correspondem à planta inteira (colmos e folhas), que não representa a forragem consumida pelos animais quando o capim-elefante é utilizado sob pastejo. Nesta forma de utilização, os animais selecionam predominantemente folhas e perfilhos novos, que, certamente, apresentam teor de PB mais elevado.

Os clones de capim-elefante apresentaram, respectivamente, 75,64 e 43,87\% de FDN e FDA, com valores máximo dos, pesando em torno de $550 \mathrm{~kg}$. Após a retirada do rúmem, 
Tabela 3 - Teores de PB, FDN e FDA de clones de capimelefante, Vitória de Santo Antão - PE

Table 3 - Contents of CP, NDF, and ADF of elephantgrass clones, Vitória de Santo Antão - PE

\begin{tabular}{llccc}
\hline Grupo & Clone & PB & FDN & FDA \\
Group & Clone & $C P$ & NDF & ADF \\
\hline \multirow{4}{*}{ I $^{1}$} & & & $\%$ & \\
& & & & \\
& Cameroon & 3,44 & 76,76 & 43,67 \\
& Mercker México & 5,92 & 76,04 & 42,27 \\
& Três Rios & 6,78 & 77,03 & 42,87 \\
& Elefante de Pinda & 4,33 & 74,00 & 44,34 \\
& Guaçu/IZ & 4,85 & 71,49 & 42,53 \\
\hline II $^{2}$ & CE 08 A.D. & 4,85 & 71,49 & 42,53 \\
& Taiwan A-25 & 4,85 & 74,13 & 42,80 \\
& Goiano & 5,93 & 76,26 & 44,62 \\
& CE 03 A.D. & 5,86 & 78,05 & 45,55 \\
& Merc & 4,83 & 77,56 & 44,70 \\
\hline
\end{tabular}

Média $\pm \mathrm{IC}^{3}$

$5,02 \pm 0,80 \quad 75,64 \pm 1,434 \quad 3,87 \pm 0,86$

Mean $\pm C I$

$\mathrm{CV}^{4}(\%)$

2,05

2,63

2,75

1 Grupo de clones de alta relação F/C (Cameroon, Mercker México, Três Rios, Elefante de Pinda e Guaçu/IZ)

2 Grupo de clones de baixa relação F/C (CE 8 A.D., Taiwan A-25, Goiano, CE 3 A.D. e Merc.

${ }^{3}$ IC $=$ Intervalo de confiança para média a $95 \%$ de probabilidade.

${ }^{4} \mathrm{CV}=$ Coeficiente de variação.

1 Group of clones with high L/S (Cameroon, Mercker México, Três Rios, Elefante de Pinda e Guaçu/IZ).

${ }^{2}$ Group of clones with low L/S (CE 8 A.D., Taiwan A-25, Goiano, CE 3 A.D. e Merc.)

${ }^{3} \mathrm{Cl}=$ Mean confidence interval at $95 \%$ probability.

${ }^{4} \mathrm{CV}=$ Coefficient of variation.

e mínimo de 78,05 e 71,00\% de FDN para os clones CE 03 A.D. e Guaçu/IZ e 45,55 e 42,27\% de FDA para os clones CE 03 A.D. e Mercker México. Os teores de FDN dos clones apresentaram maior variação que os de FDA, indicando, provavelmente, maior variação no teor de hemicelulose que nos de celulose e lignina.

O teor de FDN representa a fração química da planta que possui estreita correlação com consumo. Portanto, valores de FDN superiores a $60 \%$ se correlacionam negativamente ao consumo de forragem (Mertens, 1994). De forma semelhante, forragens com teores de FDA em torno de 30\% (nível ideal para consumo satisfatório) ou menos são consumidas em maior proporção que aquelas com teores acima de $40 \%$, (Nussio et al., 1998). Ressalta-se que, à medida que aumentam os teores de FDN e FDA, ocorre redução do NDT da forragem em virtude da menor concentração do conteúdo celular, pelo espessamento da parede celular, no qual estão presentes os componentes fibrosos, limitando a energia disponível para os ruminantes. De acordo com Prada e Silva et al. (2000), os componentes da parede celular mostraram-se negativamente correlacionados à degradabilidade da MS.

Santos et al. (2003), na Zona da Mata de Pernambuco, nos cultivares Pioneiro e Mott, respectivamente, aos 35 dias de idade, encontraram teores de PB, FDN e FDA de 10,20 e $8,5 \%$; 68, 08 e $69,61 \%$; e $38,32 \%$ e $36,92 \%$, superiores aos obtidos neste estudo. Queiroz et al. (2000b) demonstraram que o cultivar Roxo apresentou 8,6; 71,3 e 41,3\% de PB, FDN e FDA, respectivamente, aos 60 dias de idade, considerando a média anual, enquanto Lacerda et al. (2004) relataram que o capim-elefante manejado sob capineira a 1,80 m de altura apresentou 5,72 e 79,79\% de PB e FDN, respectivamente. Esses resultados corroboram a afirmação de Silva et al. (2002) de que a composição química de genótipos de capim-elefante parece ser extremamente influenciada por fatores como intervalos de corte ou ciclos de pastejo, condições climáticas, níveis de nutrientes do solo, entre outros.

Os dois grupos de clones de capim-elefante não apresentaram diferenças significativas $(\mathrm{P}>0,05)$ para a DISMS nos tempos de incubação estudados, indicando que a relação $\mathrm{F} / \mathrm{C}$ não promoveu efeito sobre essa característica (Tabela 4). As curvas de degradação da MS para os grupos de clones de capim-elefante apresentaram tendência semelhante, com coeficiente de determinação $\left(\mathrm{R}^{2}\right)$ de $63 \%$ para os dois grupos estudados.

Para as características da degradação da MS, foram determinados valores bem próximos para os dois grupos de clones de capim-elefante, com médias iguais a 79,40; 69,$10 ; 26,90 ; 52,60 ; 20,60$ e $5,50 \% / \mathrm{h}$ para degradabilidade potencial, degradabilidade efetiva, fração solúvel, fração potencialmente degradável, fração não degradada e taxa de degradação, respectivamente (Tabela 4). Verificou-se, no entanto, degradação da MS ligeiramente superior para o grupo de maior relação $\mathrm{F} / \mathrm{C}$, possivelmente em razão da maior quantidade de folhas e de tecidos não-estruturais, menos lignificados que os tecidos do colmo.

Destaca-se que a fração solúvel da matéria seca é prontamente degradada pelos microrganismos ruminais, contribuindo para a rápida diminuição do $\mathrm{pH}$ do rúmen. A fração potencialmente degradável reflete a proporção da MS degradada a determinada taxa. À medida que a taxa de degradação aumenta, a quantidade de energia disponível para os microrganismos do rúmen por unidade de tempo se torna maior.

As degradabilidades potencial e efetiva obtidas para os grupos de clones de capim-elefante (80,3 e 78,5\%; e 69,49 e $68,41 \%$ para os GRUPOS I e II, respectivamente) evidenciam que, independentemente da relação $\mathrm{F} / \mathrm{C}$, os materiais avaliados apresentaram alta degradabilidade potencial e efetiva. Neste trabalho, a degradabilidade potencial média foi um pouco inferior e a degradabilidade efetiva média superior às obtidas por Lopes et al. (2003), de 84,8 e 42,16\%, respectivamente, para extrusa de capim-elefante manejado 
Tabela 4 - Degradabilidade in situ (DISMS) e características da degradação ruminal da MS (degradabilidade potencial - DP, degradabilidade efetiva - DE, fração solúvel - FS, fração potencialmente degradável - FPD, fração não degradada - FND, taxa de degradação - TD) de acordo com a relação folha/colmo (F/C) de clones de capim-elefante, Vitória de Santo Antão - PE

Table 4 - In situ dry matter degradability (ISDMD) and ruminal dry matter degradability characteristics (potential degradability - PD, effective degradability - ED, soluble fraction - SF, potentially degradable fraction - PDF, non-degradable fraction - Non-DF, degradability rate - DR) as a function of the leaf/stem ratio (L/S) of elephantgrass clones, Vitória de Santo Antão, PE

\begin{tabular}{|c|c|c|c|c|}
\hline \multirow{2}{*}{$\begin{array}{l}\text { Tempo (h) } \\
\text { Time (h) }\end{array}$} & \multicolumn{4}{|c|}{$\begin{array}{l}\text { DISMS } \\
\text { ISDMD }\end{array}$} \\
\hline & Grupo $I^{1}$ & Grupo $\mathrm{II}^{2}$ & Média & $\mathrm{CV}$ \\
\hline & \multicolumn{4}{|c|}{$\%$} \\
\hline 0 & 27,40 & 26,60 & 27,00 & 7,22 \\
\hline 24 & 69,00 & 68,10 & 68,50 & 3,16 \\
\hline 48 & 76,60 & 75,60 & 76,10 & 2,55 \\
\hline 72 & 78,70 & 77,30 & 78,00 & 2,75 \\
\hline \multirow[t]{2}{*}{96} & 79,60 & 78,30 & 78,90 & 2,72 \\
\hline & \multicolumn{4}{|c|}{$\begin{array}{l}\text { Característica da degradação ruminal da MS } \\
\text { Ruminal dry matter degradability characteristics }\end{array}$} \\
\hline FPD (\%) (PDF, \%) & 53,20 & 51,90 & 52,60 & \\
\hline FND $(\%)(N D F, \%)$ & 19,60 & 21,50 & 20,60 & \\
\hline TD $(\% / h)(D R, \% / h)$ & 5,00 & 6,00 & 5,50 & \\
\hline
\end{tabular}

${ }_{1}^{1}$ Grupo de clones de alta relação F/C (Cameroon, Mercker México, Três Rios, Elefante de Pinda e Guaçu/IZ).

2 Grupo de clones de baixa relação F/C (CE 08 A.D., Taiwan A-25, Goiano, CE 03 A.D. e Merc).

1 Group of clones with high L/S (Cameroon, Mercker México, Três Rios, Elefante de Pinda and Guaçu/IZ).

2 Group of clones with low L/S (CE 8 A.D., Taiwan A-25, Goiano, CE 03 A.D. e Merc.).

em sistema de lotação rotacionada, com três dias de ocupação e 30 de descanso.

As degradabilidades potencial e efetiva da MS dos grupos também foram próximas àquelas obtidas para cultivares de alfafa, forrageira de alta qualidade, que variaram de 81,63 a $78,71 \%$ e de 74,09 a $57,28 \%$, respectivamente (Evangelista et al., 2002). A qualidade da forragem dos clones estudados pode ser considerada alta se avaliada pela taxa de degradação da MS, cujos valores determinados foram 5 e $6 \% / \mathrm{h}$ para os grupos I e II, respectivamente. Segundo Sampaio (1988), alimentos vegetais de boa qualidade geralmente apresentam taxa de degradação da MS de 2 a $6 \% / \mathrm{h}$

A ausência de diferença na degradabilidade in situ da MS entre os grupos de capim-elefante pode ser explicada pela redução na taxa de crescimento dos clones durante o período seco, em virtude do estresse hídrico, promovendo poucas alterações estruturais até os 60 dias de idade. Dessa forma, é possível que os clones não tenham se desenvolvido o suficiente para que houvesse diferenças marcantes nos tecidos das folhas e dos colmos. Deschamps et al. (1998) demonstraram que a digestibilidade da MS do capimelefante aos 42 dias de crescimento não difere entre as frações folhas e colmos (64,4 e 64,8\%, respectivamente).
De acordo com Buxton (1996), freqüentemente o ambiente exerce influência na qualidade da forragem, não somente por alterar a relação folha/colmo, mas também por modificar o crescimento da planta e promover mudanças na composição química de seus componentes. Dessa forma, o autor ressalta que o estresse hídrico moderado normalmente atrasa a maturação da planta, diminuindo a taxa de redução na qualidade da forragem.

Barreto et al. (2001) relataram que o desenvolvimento de clones Pennisetum sp., medido pela altura da planta, pelo número de internódio por perfilhos e pelo comprimento e largura de lâmina foliar, independentemente do genótipo, foi afetado pelo estresse hídrico, que atrasou o crescimento dos clones. O efeito do período seco sobre clones de capimelefante foi demonstrado por Andrade et al. (2003), que observaram semelhança nos teores de FDN entre os clones em função das piores condições climáticas para o crescimento e desenvolvimento das plantas.

Duas hipóteses podem ser utilizadas para explicar a degradabilidade in situ da MS dos clones neste trabalho. A primeira é que o estresse hídrico pode ter afetado o padrão de deposição da fibra, notadamente da lignina, na parede celular, facilitando o acesso das enzimas microbianas e a quebra das ligações químicas de seus componentes, de 
forma a contribuir para a degradabilidade in situ da MS e para as características da degradação ruminal nos clones de capim-elefante, apesar de os teores de PB terem sido baixos e os de FDN e FDA, altos.

Segundo Rodrigues et al. (2004), a susceptibilidade à degradação ruminal da porção fibrosa varia entre espécies e com a idade ou o nível de maturação da forrageira. À medida que a planta se desenvolve, ocorre drástica redução do teor protéico e aumento do teor de fibra, associado à elevação no teor de lignina. A lignina forma uma barreira que impede a aderência microbiana e a hidrólise enzimática da celulose e hemicelulose, indisponibilizando os carboidratos estruturais potencialmente degradáveis e diminuindo a digestibilidade da MS.

A segunda hipótese seria a de que o padrão de deposição da fibra, independentemente do estresse hídrico, foi governado geneticamente pelos clones, indicando materiais superiores quanto à degradabilidade dos componentes fibrosos, uma vez que esses componentes tiveram alta participação na MS. Dessa forma, seriam necessários estudos mais específicos para comprovar essa premissa.

\section{Conclusões}

A degradabilidade in situ da matéria seca de clones de capim-elefante não é influenciada pela relação folha/colmo durante o período seco do ano.

\section{Agradecimento}

Ao CNPq, pela concessão de bolsa, e aos autores Mércia Virgínia Ferreira dos Santos, Mário de Andrade Lira e Rinaldo Luiz Caraciolo Ferreira.

\section{Literatura Citada}

ANDRADE, A.C.; FONSECA, D.M.; QUEIROZ, D.S. et al. Adubação nitrogenada e potássica em capim-elefante (Pennisetum purpureum Schum. cv. napier). Ciência e Agrotecnologia, edição especial, p.1643-1651, 2003.

ANUÁRIO ESTATÍSTICO DE PERNAMBUCO. Recife: IBGE, 1991. V.40.

BARRETO, G.P.; LIRA, M.A.; SANTOS, M.V.F. et al. Avaliação de clones de capim-elefante (Pennisetum purpureum Schum.) e de um híbrido com o milheto (Pennisetum glaucum (L.) R. Br.) submetidos a estresse hídrico. 1. Parâmetros morfológicos. Revista Brasileira de Zootecnia, v.30, n.1, p.1-6, 2001.

BUXTON, D.R. Quality-related characteristics of forages as influenced by plant environment and agronomic factors. Animal Feed Science and Technology, v.59, n.1, p.3749, 1996.

CHERNEY, D.J.R.; MERTENS, D.R.; MOOR, J.E. Intake and digestibility by wethers as influenced by forage morphology at three levels of forage offering. Journal of Animal Science, v.68, n.12, p.4345-4351, 1990.

DESCHAMPS, F.C.; EMMEL, A.; RAMOS, L.P. Modificações químicas observadas na parede celular do capim-elefante ao longo de 126 dias. In: REUNIÃO ANUAL DA SOCIEDADE BRASILEIRA DE ZOOTECNIA, 35., 1998, Botucatu. Anais... Botucatu: Sociedade Brasileira de Zootecnia, 1998. p.131-133.

ENCARNAÇÃO, C.R.F. Observações meteorológicas e tipos climáticos das unidades e campos experimentais da Empresa IPA. Recife: IPA, 1980. 110p.

EVANGELISTA, A.R.; SALES, E.C.J.; TEIXEIRA, J.C. et al Degradabilidade ruminal da matéria seca e proteína bruta de cultivares de alfafa (Medicago sativa L.). Ciência e Agrotecnologia, v.26, n.6, p.1281-1288, 2002.

FISHER, D.S. A review of a few key factors regulating voluntary feed intake in ruminants. Crop Science, v.42, n.5, p.16511655, 2002.

FREITAS, E.V.; LIRA, M.A.; DUBEUX JR., J.C.B. et al Características produtivas e qualitativas de clones de capimelefante (Pennisetum purpureum Schum.) avaliados sob pastejo na Zona da Mata de Pernambuco. Acta Scientiarum.Animal Sciences, v.26, n.2, p.251-257, 2004.

GRABBER, J.H.; RALPH, J.; LAPIERRE, C. et al. Genetic and molecular basis of grass cell-wall degradability. I. Lignin-cell wall matrix interactions. Comptes Rendus Biologies, v. 327 , n.5, p.455-465, 2004.

LACERDA, P.D.; MALAFAIA, P.; VIEIRA, R.A.M. et al. Variação anual da composição bromatológica de duas forrageiras cultivadas nas baixadas litorâneas do Estado do Rio de Janeiro, Brasil. Ciência Rural, v.34, n.2, p.523-529, 2004.

LOPES, F.C.F.; AROEIRA, L.J.M.; RODRIGUEZ, N.M. et al Degradação ruminal in situ do capim-elefante (Pennisetum purpureum, Schumack) consumido sob pastejo por vacas mestiças Holandês $\times$ Zebu em lactação. Arquivo Brasileiro de Medicina Veterinária e Zootecnia, v.55, n.6, p.694-701, 2003.

LOPES, R.S.; FONSECA, D.M.; CÓSER, A.C. et al. Avaliação de métodos para estimação da disponibilidade de forragem em pastagem de capim-elefante. Revista Brasileira de Zootecnia, v.29, n.1, p.40-47, 2000.

MELLO, A.C.L.; LIRA, M.A.; DUBEUX JR., J.C.B. et al Caracterização e seleção de clones de capim-elefante (Pennisetum purpureum Schum.) na Zona da Mata de Pernambuco. Revista Brasileira de Zootecnia, v.31, n.1, p.30-42, 2002

MERTENS D.R. Regulation of forage intake. In: FAHEY JR., D.C. (Ed.) Forage quality, evaluation and utilization. Madison: American Society of Agronomy, 1994. p.450-492.

MINSON, D.J.; WILSON, J.R. Prediction of intake as on element of forage quality. In: FAHEY JR., G. (Ed.) Forage quality, evaluation, and utilization. Madson: American Society of Agronomy, 1993. p.533-563.

NOCEK, J.E. In situ and other methods to estimate ruminal protein and energy digestibility: Review. In: SIMPÓSIO INTERNACIONAL DE DIGESTIBILIDADE EM RUMINANTES, 1997, Lavras. Anais... Lavras: Universidade Federal de Lavras, 1997. p. 197-240

NUSSIO, L.G.; MANZANO, R.P.; PEDREIRA, C.G.S. Valor alimentício em plantas do gênero Cynodon. In: SIMPÓSIO SOBRE MANEJO DA PASTAGEM, 1998, Piracicaba. Anais... Piracicaba: Fundação de Estudos Agrários Luiz de Queiroz, 1998. p. 203-242.

RSKOV, E.R.; HOVELL, F.D.; MOULD, F. The use of the nylon bag technique for evaluation of feedstuffs. Tropical Animal Production, v.5, n.3, p.195-21, 1980.

ORSKOV, E.R.; McDONALD, J. The estimation of protein degradability in the from incubation measurements weighted acoording to rate of passage. Journal of Agricultural Science, v.92, n.2, p.499-503, 1979.

PEREIRA, A.V.; FERREIRA, R.P.; PASSOS, L.P. et al. Variação da qualidade de folhas em cultivares de capim-elefante (Pennisetum 
purpureum) e híbridos de capim-elefante $\mathrm{x}$ milheto (P. purpureum x $P$. glaucum), em função da idade da planta. Ciência e Agrotecnologia, v.24, n.2, p.490-499, 2000.

PRADA e SILVA, L.F.; MACHADO, P.F.; FRANCISCO JR., J.C. et al. Relação entre a composição química e a degradabilidade in situ da matéria seca e da fibra em detergente neutro da fração volumosa de híbridos de milho. Revista Brasileira de Zootecnia, v.29, n.1, p.288-294, 2000.

QUEIROZ, D.S.; GOMIDE, J.A.; MARIA, J. Avaliação da folha e do colmo de topo e base de perfilhos de três gramíneas forrageiras. 2. Anatomia. Revista Brasileira de Zootecnia, v.29, n.1, p.61-68, 2000a.

QUEIROZ, D.S.; GOMIDE, J.A.; MARIA, J. Avaliação da folha e do colmo de topo e base de perfilhos de três gramíneas forrageiras. 1. Digestibilidade in vitro e composição química. Revista Brasileira de Zootecnia, v.29, n.1, p.53-60, 2000 b. RODRIGUES, A.L.P.; SAMPAIO, I.B.M.; CARNEIRO, J.C. et al. Degradabilidade in situ da matéria seca de forrageiras tropicais obtidas em diferentes épocas de corte. Arquivo Brasileiro de Medicina Veterinária e Zootecnia, v.56, n.5, p.658664, 2004.

SAMPAIO, I.B.M. Experimental designs and modeling techniques in the study of roughage degradation in rumen and growth of ruminants. Reading: University of Reading, 1988. 214p. Tese (Doctor in Physiology) - University of Reading, 1988.
SANTOS, M.V.F.; DUBEUX JR., J.C.B.; SILVA, M.C. et al. Produtividade e composição química de gramíneas tropicais na Zona da Mata de Pernambuco. Revista Brasileira de Zootecnia, v.32, n.4, p.821-827, 2003.

SILVA, D.J.; QUEIROZ, C. Análise de alimentos (Métodos químicos e biológicos). 2.ed. Viçosa, MG: Universidade Federal de Viçosa, 2002. 235p.

SILVA, M.M.P.; VASQUEZ, H.M.; SILVA, J.F.C. et al. Composição bromatológica, disponibilidade de forragem e índice de área foliar de 17 genótipos de capim-elefante (Pennisetum purpureum Schum.) sob pastejo, em Campos dos Goytacazes, RJ. Revista Brasileira de Zootecnia, v.31, n.1, p.313-320, 2002.

THORNTHWAITE, C.W.; MATTER, J.R. The water oudget and its use irrigation. In: THORNITHWAITE, C.W.; MATTER, J.R. (Eds.) Water the year book of agriculture. Washington: USDA, 1995. p.356-358. 